\title{
Short communication: Effects of mammary biopsy in the dry period on activity and feeding behavior of dairy cows
}

\author{
E. K. Miller-Cushon, ${ }^{*}$ (i) K. C. Horvath, (1) T. F. Fabris, G. E. Dahl, (1) and J. Laporta (1) \\ Department of Animal Sciences, University of Florida, Gainesville 32611
}

\section{ABSTRACT}

In dairy cattle, mammary biopsies are commonly used to study development and function of the mammary gland. The objective of this study was to investigate changes in activity and feeding patterns following the mammary biopsy procedure. Pregnant, nonlactating Holstein dairy cows ( $20 \mathrm{~d}$ before expected calving date) were exposed to either (1) a biopsy procedure, in which a mammary tissue sample $(60 \times 4 \mathrm{~mm}$ in diameter $)$ was obtained from cows $(\mathrm{n}=9)$ using a biopsy tool from the rear left quarter, following administration of a sedative (xylazine, $20 \mu \mathrm{g} / \mathrm{kg}$ of body weight) and local anesthetic (3 mL of lidocaine), or (2) a sham procedure, in which cows $(\mathrm{n}=8)$ were removed from the pen and restrained for a similar duration of time as for the biopsy procedure. Behavior of cows was monitored for $5 \mathrm{~d}$, beginning on the day following biopsy (approximately $14 \mathrm{~h}$ after the procedure). Cows were fitted with accelerometers to record daily lying time, lying bout frequency, and lying side. Daily individual feed intake was recorded using the Calan Broadbent feeding system, and feeding time and meal characteristics were determined from a subset of cows ( $\mathrm{n}=6$ per treatment) using a change-of-state data logger to record the times the cows were accessing the feed bunk. Total daily lying time did not differ between treatments $[13.9 \mathrm{~h} / \mathrm{d}$; standard error $(\mathrm{SE})=0.56]$, but biopsied cows had more frequent, shorter lying bouts on the biopsied side on d 1 following the procedure (6.67 vs. 4.25 bouts/d, $\mathrm{SE}=1.03$, and 70.0 vs. $97.0 \mathrm{~min} /$ bout, $\mathrm{SE}=8.6$; left vs. right side), whereas control cows had no side preference. We found no effects of treatment on feed intake and feeding time but, on the first day after treatment, biopsied cows had meals that were more frequent $(7.2$ vs. 4.6 meals $/ \mathrm{d} ; \mathrm{SE}=0.93)$ and tended to be shorter ( 28.2 vs. $60.9 \mathrm{~min} / \mathrm{meal} ; \mathrm{SE}=11.8)$ than control cows. In conclusion, we did not detect effects of mammary biopsy on feed intake or lying time during our time frame

Received May 22, 2019.

Accepted August 26, 2019.

*Corresponding author: emillerc@ufl.edu of observation, but activity patterns were altered, which could be indicative of increased overall restlessness and specific pain in the biopsied quarter.

Key words: dairy cow, mammary biopsy, lying time, feeding behavior

\section{Short Communication}

In dairy cattle, mammary biopsies are commonly used to study mammary development and function (Weng et al., 2017; Skibiel et al., 2018). It is common practice to apply analgesic and local anesthetic for this procedure, yet post-biopsy inflammation may also cause pain. It is well established that painful procedures are associated with behavioral changes (reviewed by Adcock and Tucker, 2018); such procedures include castration (Thüer et al., 2007), dehorning (Mintline et al., 2013), and other surgeries (e.g., fistulation surgery; Newby et al., 2014). Activity patterns often respond to pain, with lying time either increasing (as in lame cattle; Ito et al., 2010) or decreasing (as in cattle with mastitis; Siivonen et al., 2011), depending on the nature or source of the pain experienced by the animal.

Mammary biopsies have previously been found to have no effect on DMI or milk yield, suggesting that this procedure may not affect production (Weng et al., 2017). Previous studies suggest that behavioral changes follow liver biopsy procedures in dairy cattle (Beausoleil and Stafford, 2012; Mølgaard et al., 2012), but effects of mammary biopsy on similar behavioral changes, which may be indicative of ongoing pain, have not been evaluated. Pain associated with post-biopsy tissue inflammation may be important to consider from an animal welfare perspective, and could also result in changes to behavioral patterns, such as lying and feeding, with potential to influence experimental results.

The objective of this preliminary study was to evaluate effects of mammary biopsy on subsequent activity patterns and feeding behavior. We hypothesized that cows subjected to a mammary biopsy would exhibit changes of behavior in the home pen, including responses that may be reflective of localized pain in the wound site, such as reduced lying and changes in lying 
laterality. Further, we predicted that cows may alter feeding behavior and patterns of rest, which may be expected as a generalized response to inflammation or if experiencing this procedure results in a pervasive negative mood.

Pregnant, multiparous Holstein cows were housed at the Dairy Unit of the University of Florida (Hague, FL). Cows used in this study were a subset of a largerscale study, and general housing and management procedures are described in full by Fabris et al. (2017). In brief, cows were dried off at approximately $45 \mathrm{~d}$ before expected calving, housed in a freestall barn, and provided active cooling using fans and soakers over the feed bunks (pen temperature-humidity index of 77.6 during the experimental period; Fabris et al., 2017). All cows were fed a common prepartum TMR (see Fabris et al., 2017, for composition) during the entire dry period. At $20 \mathrm{~d}$ before expected calving dates, cows received a mammary biopsy (Biopsy; $\mathrm{n}=9$ ). Each cow set to receive a mammary biopsy was paired with a cow at a similar stage of pregnancy (within $6.9 \pm 3.8$ $\mathrm{d}$ of the same expected calving date), who received a sham procedure on the same day (Control). Sample size was determined based on previous research examining behavioral changes (including lying and feeding time, as measured in the present study) associated with liver biopsy in dairy cattle (Beausoleil and Stafford, 2012; Fogsgaard et al., 2012). Due to missing data in our final analysis, as described below, we performed a post hoc calculation to estimate the effect sizes we were able to detect at $80 \%$ power (PROC POWER of SAS v. 9.4; SAS Institute, Cary, NC). This calculation suggested that we were able to detect differences of approximately $20 \%$ for lying characteristics (effect sizes of $2 \mathrm{~h}$ of lying and 2 bouts/d) and differences of approximately 30\% in feeding behavior characteristics (effect sizes of 60 min of feeding time and 3 meals/d). All experimental procedures were approved by the University of Florida Institutional Animal Care and Use Committee.

For the biopsy procedure, cows were brought into a handling chute, sedated by jugular injection of xylazine (Akom Inc., Decatur, IL) at a concentration of $20 \mathrm{mg} /$ $\mathrm{mL}$ and a dose of $35 \mu \mathrm{L} / \mathrm{kg}$ of $\mathrm{BW}$. The region to be biopsied (in the middle of the rear left quarter for all cows) was shaved and sanitized 3 times by scrubbing with iodine, followed by rinsing with $70 \%$ ethanol. Local anesthesia was achieved via subcutaneous injection of $3 \mathrm{~mL}$ of lidocaine HCL (Phoenix Pharmaceuticals, Burlingame, CA) administered in a line block above the biopsy site. A 2- to 3-cm incision was made through skin and connective tissue, with care taken to avoid obvious blood vessels. Mammary tissue $(60 \times 4 \mathrm{~mm}$ in diameter) was obtained using a mammary biopsy tool (Farr et al., 1996) with a cordless drill (18V, Black
\& Decker, Towson, MD). Incisions were closed using 18-mm stainless steel Michel wound-clips and sprayed with antiseptic wound dressing. Following the procedure, incisions were checked daily by trained personnel until full recovery and clip removal. Control cows were brought into the handling chute in the same way as MB cows and restrained for a similar period of time (approximately $15 \mathrm{~min}$ ). Cow handling and all biopsy procedures were performed between 0800 and $1000 \mathrm{~h}$. Following the biopsy or sham procedure, all cows were released back into a holding pen (located adjacent to the handling area, a fenced section of pasture, approximately $150 \mathrm{~m}^{2}$, containing a water trough) for initial recovery and subsequently to the freestall barn. Milk yield was measured daily during the first 9 weeks after calving, to measure any effects of the biopsy procedure on subsequent production.

To assess effects of the biopsy procedure on behavior, observations were conducted beginning on the day following the procedure, so that biopsied cows would no longer be subject to effects of sedation or local anesthesia. Lying behavior was recorded using electronic accelerometers (HOBO Pendant G Data Logger, Onset Computer Corp., Pocasset, MA) that record leg orientation in 1-min intervals (Ledgerwood et al., 2010). Data loggers were placed on the hind limb of each cow before the biopsy or sham procedure, and data were analyzed for $5 \mathrm{~d}$ (beginning at $0000 \mathrm{~h}$ on the day following the procedure, approx. $14 \mathrm{~h}$ post-biopsy). Data were summarized from data loggers to determine total daily lying time, number of lying bouts, and duration of lying on each side. One data set was excluded due to logger malfunction (Control treatment).

Dry matter intake was measured from individual cows using the Calan Broadbent Feeding System (American Calan Inc., Northwood, NH) for $5 \mathrm{~d}$ postbiopsy (beginning at $0000 \mathrm{~h}$ on the day following the procedure, approx. $14 \mathrm{~h}$ post-biopsy). Daily time spent feeding and meal characteristics of individual cows were also determined during this time frame based on visits to the Calan gates, which were recorded using a HOBO change-of-state data logger (Onset Computer Corp.; validated by Krawczel et al., 2012). The logger was mounted to the door shell and latch plate and recorded feeding behavior for $5 \mathrm{~d}$, with data analyzed beginning at the time of feed delivery on the day following the biopsy or sham procedure. These data were screened as described by Krawczel et al. (2012) to eliminate visits of duration of less than $3 \mathrm{~s}$ (which likely reflected jostling of the gate or a cow not fully reaching the feedbunk before the gate closed) or visits of $5,400 \mathrm{~s}$ or longer (which likely reflected a failure of the data logger to align properly; $2 \%$ of all observations). Due to logger malfunction (failure of the mounting bracket resulting 
in displacement of the logger), data were available for 6 cows per treatment.

Data were summarized from the change-of-state data loggers to determine daily time spent feeding (defined as door open). Further, data describing duration of and interval between visits to the feed bunk were subjected to bout analysis according to methods described previously (Horvath and Miller-Cushon, 2019). Based on initial visual inspection of the data, interval distributions were similar among animals, and so this analysis was performed on data pooled across all animals. Briefly, the $\log _{10}$ frequent distributions of interval lengths between visits to the feedbunk were modeled using a mixture of 2 normal distributions (using the $\mathrm{R}$ package mixdist; Macdonald and $\mathrm{Du}, 2018$ ). Based on conditional probabilities generated within the mixdist package, the meal criterion was determined as the point at which the first distribution curve crossed the second distribution curve (where the 2 curves are interpreted as intervals within and between meals, respectively). The meal criterion was calculated as 26.4 min. Based on this determined criterion, meal characteristics were calculated for each cow and day of observation as meal frequency (counted as the number of intervals between visits that exceeded the criterion), meal time (sum of feeding time and intervals between visits that were shorter than the bout criterion), and average meal duration (meal time divided by meal frequency).

Activity data (daily standing bout frequency and duration), feeding behavior data (feeding time, meal frequency, and meal duration), and feed intake were analyzed using a repeated measures general linear mixed model (PROC MIXED of SAS v. 9.4), treating day as a repeated measure with cow as subject. The model included the fixed effects of treatment (MB or CON), day, and treatment $\times$ day interaction. The autoregressive model was selected as the variance-covariance matrix structure on the basis of best fit according to the Schwarz Bayesian information criterion. Test degrees of freedom were 1 for tests of treatment effect and 4 for tests of day and treatment $x$ day effects. Error degrees of freedom were estimated using the Kenward-Roger approximation. Lying laterality was analyzed using the above model plus split-plot effects to examine the effects of lying side and its interactions. All response variables were screened for normality before analysis (using PROC UNIVARIATE of SAS). All values reported are least squares means. Significance was declared at $P<$ 0.05 and trends reported at $0.05 \leq P \leq 0.10$.

Total daily lying time was not significantly affected by mammary biopsy, but biopsied cows had more frequent lying bouts and shorter lying bout durations overall following biopsy (Table 1). When lying behavior was analyzed accounting for side effects, this effect was particularly apparent on the first day following biopsy. Lying bout frequency per side was affected by biopsy (treatment $\times$ side $\times$ day interaction; $P=0.019$; Figure 1a), with biopsied cows having more frequent lying bouts on the biopsied side on $\mathrm{d} 1$ post-biopsy (6.67 vs. 4.25 bouts/d, left vs. right side; $\mathrm{SE}=1.03 ; P=$ $0.027)$, whereas control cows had no significant side preference ( 5.8 vs. 5.3 bouts/d, left vs. right side; $\mathrm{SE}=$ 1.08; $P=0.82$ ). Lying bout duration per side similarly tended to differ between treatments (treatment $\times$ side $\times$ day interaction; $P=0.066$; Figure $1 \mathrm{~b}$ ), with biopsied cows having shorter lying bouts on the left on d 1 (70.0 vs. $97.0 \mathrm{~min} /$ bout, left vs. right side; $\mathrm{SE}=8.61 ; P=$ 0.033), whereas Control cows did not have a significant side preference $(P=0.94)$. Lying bout frequency and duration did not differ between sides for either treatment on subsequent days $(P>0.3)$.

Lying is a highly motivated behavior in dairy cattle (Jensen et al., 2005) but may be reduced in cases of localized injury that affect lying comfort. Cows with inflammation of the udder during mastitis have lower response thresholds to mechanical stimulation (Fitzpatrick et al., 2013) and exhibit reduced lying time (Siivonen et al., 2011; Cyples et al., 2012). However, changes in lying time are not consistently observed for mild surgical procedures. Previous studies have noted no effect of liver biopsies on total lying time duration or lying bout frequency, in either the first $4 \mathrm{~h}$ post-biopsy

Table 1. Daily lying time, lying bout frequency, and average lying bout duration among dairy cows following mammary biopsy in the left rear quarter (Biopsy, $\mathrm{n}=9$ ) or a sham procedure (Control, $\mathrm{n}=8$ ), measured for $5 \mathrm{~d}$ (D) beginning the day following treatment (approximately $14 \mathrm{~h}$ post-biopsy)

\begin{tabular}{|c|c|c|c|c|c|c|}
\hline \multirow[b]{2}{*}{ Item } & \multicolumn{2}{|c|}{ Treatment $(\mathrm{T})$} & \multirow[b]{2}{*}{$\mathrm{SE}$} & \multicolumn{3}{|c|}{$P$-value ${ }^{1}$} \\
\hline & Biopsy & Control & & $\mathrm{T}$ & $\mathrm{D}$ & $\mathrm{T} \times \mathrm{D}$ \\
\hline Lying time, $\mathrm{h} / \mathrm{d}$ & 14.2 & 13.5 & 0.56 & 0.32 & 0.51 & 0.25 \\
\hline Lying bouts, no./d & 11.8 & 9.9 & 0.57 & 0.017 & 0.11 & 0.83 \\
\hline Lying bout duration, $\min /$ bout & 74.7 & 84.4 & 4.26 & 0.074 & 0.20 & 0.84 \\
\hline
\end{tabular}

${ }^{1}$ Test degrees of freedom were 1 for tests of treatment effect and 4 for tests of day and treatment $\times$ day effects. Error degrees of freedom were estimated using the Kenward-Roger approximation (approximately 15 for tests of treatment and 60 for tests of day and treatment $\times$ day effects). 


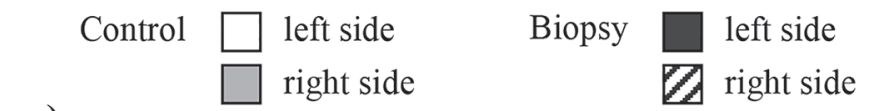

a)
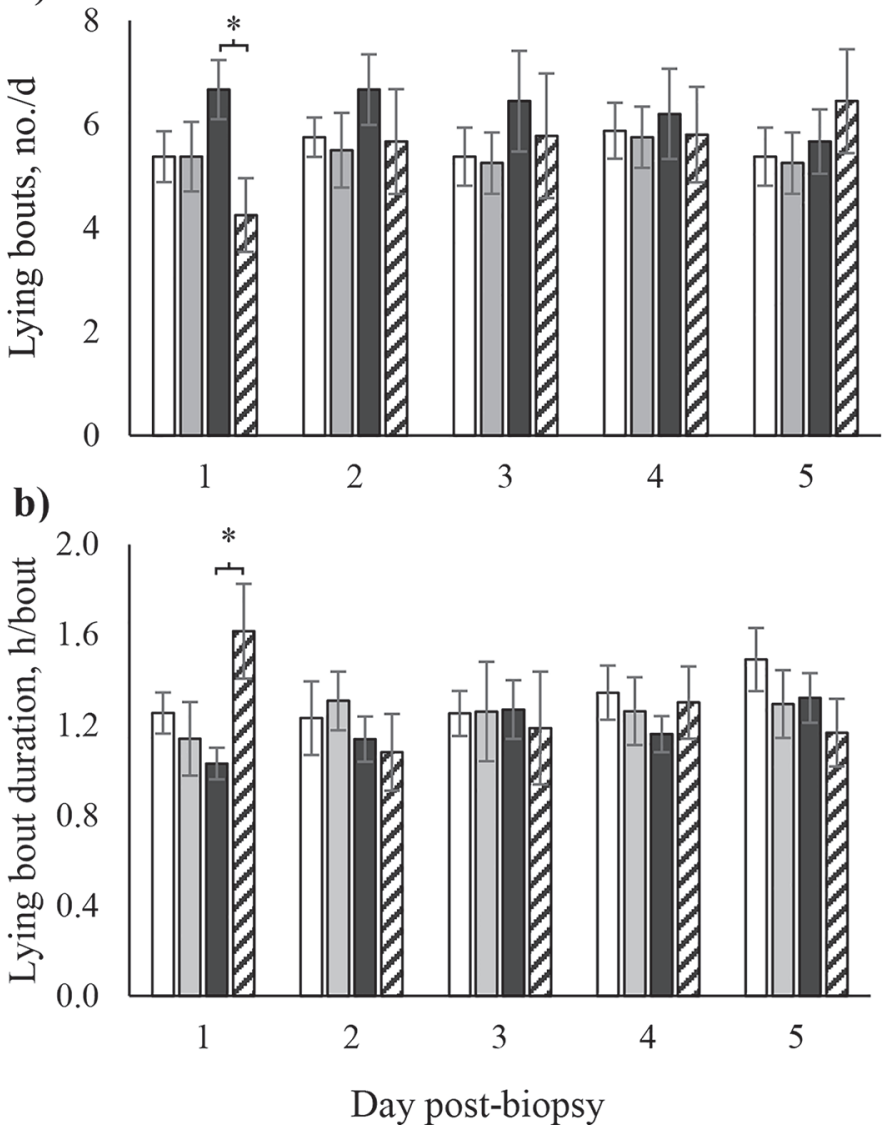

Figure 1. (a) Lying bout frequency and (b) average lying bout duration per side among dairy cows following mammary biopsy in the left rear quarter (Biopsy, $\mathrm{n}=9$ ) or a sham procedure (Control, $\mathrm{n}=8$ ), for $5 \mathrm{~d}$ beginning on the day following treatment (d 1, beginning approximately $14 \mathrm{~h}$ post-biopsy). Error bars represent SE. *An asterisk denotes a significant difference between lying sides $(P<0.05)$.
(Beausoleil and Stafford, 2012) or the day following biopsy (Mølgaard et al., 2012). However, Mølgaard et al. (2012) did note that liver biopsy increased the number of leg movements and standing time during a 6-h period during the night, indicating possible restlessness during this period. We did not find a significant effect of biopsy on total lying time, but biopsied cows had shorter and more frequent lying bouts on the left side on the first day following biopsy. This suggests that biopsied cows were more restless and may have been avoiding lying on the biopsied quarter for prolonged periods of time due to pain in that region. Changes in lying side preference are also evident following rumen fistulation surgery, with cows decreasing time lying on their left side after the procedure and exhibiting increased laterality when not provided analgesic (Newby et al., 2014). Increased overall restlessness, with more frequent changes between standing and lying, is also often associated with painful procedures (e.g., following castration; Thüer et al., 2007) and may also be interpreted more generally as a behavioral response related to the stressor of a painful experience (Mellor et al., 2000; Mølgaard et al., 2012).

Feeding time and DMI were not affected by the biopsy procedure (Table 2). Meal duration was subject to a treatment $\times$ day interaction (Table 2 ), with biopsied cows tending to have shorter meals on the first day after biopsy ( 28.2 vs. $60.9 \mathrm{~min} / \mathrm{meal}$, Biopsy vs. Control; $\mathrm{SE}=11.8 ; P=0.053)$, with no detectable difference in meal duration between treatments on following days $(P>0.23)$. Similarly, meal frequency tended to differ between treatments over time (Table 2), with biopsied cows having more frequent meals on the first day postbiopsy (7.2 vs. 4.6 meals $/ \mathrm{d} ; \mathrm{SE}=0.93 ; P=0.040$ ) and no detectable difference in meal frequency between treatments on following days $(P>0.35)$.

Table 2. Feed intake, feeding time, and meal characteristics of dairy cows following mammary biopsy in the left rear quarter (Biopsy) or a sham procedure (Control), measured for $5 \mathrm{~d}$ (D) beginning the day following treatment (approximately $14 \mathrm{~h}$ post-biopsy) ${ }^{1}$

\begin{tabular}{|c|c|c|c|c|c|c|}
\hline & \multicolumn{2}{|c|}{ Treatment $(\mathrm{T})$} & \multirow[b]{2}{*}{$\mathrm{SE}$} & \multicolumn{3}{|c|}{$P$-value ${ }^{2}$} \\
\hline & Biopsy & Control & & $\mathrm{T}$ & $\mathrm{D}$ & $\mathrm{T} \times \mathrm{D}$ \\
\hline$\overline{\mathrm{DMI}}, \mathrm{kg} / \mathrm{d}$ & 11.7 & 12.4 & 0.93 & 0.59 & 0.87 & 0.48 \\
\hline Feeding time, $\min / \mathrm{d}$ & 144.5 & 179.6 & 24.2 & 0.34 & 0.045 & 0.44 \\
\hline Meal duration, $\mathrm{min} /$ meal & 54.5 & 52.9 & 11.3 & 0.92 & 0.69 & 0.008 \\
\hline Meal frequency, no./d & 5.2 & 5.6 & 0.69 & 0.70 & 0.62 & 0.077 \\
\hline Meal time, $\mathrm{min} / \mathrm{d}$ & 213.8 & 260.4 & 31.6 & 0.31 & 0.013 & 0.26 \\
\hline
\end{tabular}

${ }^{1}$ Data are summarized for $n=9$ cows/treatment for DMI data and $n=6$ cows/treatment for feeding time and meal characteristics.

${ }^{2}$ Test degrees of freedom were 1 for tests of treatment effect and 4 for tests of day and treatment $\times$ day effects. Error degrees of freedom were estimated using the Kenward-Roger approximation (approximately 16 for tests of treatment and 64 for tests of day and treatment $\times$ day effects for DMI data, and 10 for tests of treatment and 40 for tests of day and treatment $\times$ day effects for meal characteristics). 
Cows in the present study spent somewhat less time feeding than was reported for previous studies conducted with close-up dry cows; for example, feeding times of 40 to $60 \mathrm{~min} / \mathrm{d}$ greater than the present study were reported by Hosseinkhani et al. (2008). Feeding behavior is subject to environmental effects, with feed intake decreasing during heat stress conditions (reviewed by West, 2003). In the present study, cows were in heat stress conditions when pen temperature-humidity index was 77.6 (as described in greater detail by Fabris et al., 2017), although all enrolled cows received active cooling. Consistent with previous findings (Weng et al., 2017), we found no significant effect of mammary biopsy on DMI. Similarly, Mølgaard et al. (2012) found no effect of liver biopsy on feed intake.

Although no effects of the biopsy on total feeding time or intake were revealed in the present study, differences in feeding behavior suggest that biopsied cows divided their feeding activity into shorter, more frequent meals on the day following biopsy. The implications of this difference in meal patterning are not clear. Consideration of these results in combination with the more frequent, shorter lying bouts exhibited by biopsied cows may simply reflect increased restlessness. Collection of more behavioral data in future work may provide further insight into the effects of mammary biopsy on feeding motivation. Our observed absence of effects on total feeding time or feed intake, in combination with previous findings (Mølgaard et al., 2012; Weng et al., 2017), suggests that cows prioritize maintaining feed intake, such that it may be a less useful indicator of pain, but that feeding patterns may be more sensitive to emotional or inflammatory effects of painful procedures. Feeding time and feed intake are affected by lameness (Norring et al., 2014), likely because accessing the feedbunk causes specific pain due to standing on affected limbs. In cases where the physical action of accessing the feedbunk does not specifically affect the painful region, changes in feeding behavior could be driven either by generalized inflammation and suppressed appetite (Hart, 1987) or by other avoidance of the feedbunk. For example, it could be speculated that cows subjected to a painful procedure might alter feeding patterns to prevent competitive interactions at the feedbunk, either to avoid potentially painful physical contact or possibly due to a more generalized reduced ability to cope with stressors. Co-occurrence of chronic pain and anxiety disorders is well documented in humans (Asmundson and Katz, 2009), but possible links between pain and other affective states which may affect behavior in cattle are unclear.

We found no effect of the mammary biopsy during the dry period on milk yield during the first 9 wk after calving (38.0 vs. $40.6 \mathrm{~kg} / \mathrm{d} ; \mathrm{SE}=3.4 ; P=0.59$ ). This is consistent with previous findings that mammary biopsies did not affect milk yield or composition in lactating cows (Weng et al., 2017).

The time frame of data collection in the present study allowed for determination of behavioral changes indicative of possible pain associated with post-biopsy tissue inflammation during the days following the procedure. It is important to note that, although it was not the objective of the present study to measure more acute shorter-term responses to mammary biopsy, similar surgical procedures have been found to induce changes in behavior indicative of localized pain in the affected region. During the initial hours after a liver biopsy, cows spent more time looking directly at the incision site compared with cows that received handling only (Beausoleil and Stafford, 2012) and exhibited increased tail pressing (pressing the tail against the base of the udder) and perching (body stretched and hooves placed outside the stall; Mølgaard et al., 2012), which are likely indications that the cow is experiencing some form of pain. In future work, it might be useful to measure performance of similar behaviors in the initial hours following mammary biopsy, in addition to the longerterm changes in normal behavior measured herein. This would be facilitated by inclusion of a medicated control group, to enable separation of the effects of sedative and anesthetic from the effects of the biopsy procedure on behavior immediately following the biopsy. Further, techniques designed to evaluate wound sensitivity, such as pressure algometry, might also provide insight into perception of localized pain. For example, dairy calves remain sensitive in the disbudded area for days after the procedure, in the absence of other longer-term changes in activity (Mintline et al., 2013).

This preliminary study provides the first evidence of behavioral changes following mammary biopsy, which may indicate pain. The significance of these changes, in terms of how they correlate with severity of pain experienced by the cow or corresponding negative emotional states, remains unclear. We encourage further research to examine both evoked and non-evoked indicators of pain in cows recovering from mammary biopsy, as well as characterization of the incision healing process. Observation during the time window immediately following the biopsy procedure would also shed light on the acute response, whereas longer-term research with a larger sample size and broader range of behavioral measures (including intensive observation of cues such as body posture and wound-directed behaviors) may elucidate the longevity and severity of effects of this procedure.

In conclusion, we did not detect effects of mammary biopsy on duration of feeding time or resting during our time frame of observation, but we observed that 
the mammary biopsy procedure affected patterns of activity and feeding. Biopsied cows had shorter, more frequent lying bouts, particularly on the biopsied side, and shorter, more frequent meals on the day following the biopsy. These changes suggest an increased restlessness in biopsied cows, possibly reflecting that the cows are resting less comfortably and may be experiencing pain in the biopsied quarter. We encourage further research to characterize the extent and longevity of behavioral responses to this procedure.

\section{ACKNOWLEDGMENTS}

We thank the staff at the University of Florida Dairy Unit and our undergraduate research students Amber Dewitt and Jayda Fleishman and summer interns Yazielis Martinez and Fabiana Nunes for their technical assistance. This study was conducted with funding support from the Department of Animal Sciences, University of Florida, Gainesville.

\section{REFERENCES}

Adcock, S. J. J., and C. B. Tucker. 2018. Painful procedures: When and what should we be measuring in cattle? Pages $157-198$ in Advances in Cattle Welfare. C. B. Tucker, ed. Elsevier Woodhead Publishing, Cambridge, UK.

Asmundson, G. J. G., and J. Katz. 2009. Understanding the co-occurrence of anxiety disorders and chronic pain: State-of-the-art. Depress. Anxiety 26:888-901.

Beausoleil, N. J., and K. J. Stafford. 2012. Is a nonsteroidal antiinflammatory drug required to alleviate pain behavior associated with liver biopsy in cattle? J. Vet. Behav. 7:245-251.

Cyples, J. A., C. E. Fitzpatrick, K. E. Leslie, T. J. DeVries, D. B. Haley, and N. Chapinal. 2012. Short communication: The effects of experimentally induced Escherichia coli clinical mastitis on lying behavior of dairy cows. J. Dairy Sci. 95:2571-2575.

Fabris, T. F., J. Laporta, F. N. Corra, Y. M. Torres, D. J. Kirk, D. J. McLean, J. D. Chapman, and G. E. Dahl. 2017. Effect of nutritional immunomodulation and heat stress during the dry period on subsequent performance of cows. J. Dairy Sci. 100:6733-6742.

Farr, V. C., K. Stelwagen, L. R. Cate, A. J. Molenaar, T. B. Mcfadden, and S. R. Davis. 1996. An improved method for the routine biopsy of bovine mammary tissue. J. Dairy Sci. 79:543-549.

Fitzpatrick, C. E., N. Chapinal, C. S. Petersson-Wolfe, T. J. DeVries, D. F. Kelton, T. F. Duffield, and K. E. Leslie. 2013. The effect of meloxicam on pain sensitivity, rumination time, and clinical signs in dairy cows with endotoxin-induced clinical mastitis. J. Dairy Sci. 96:2847-2856.

Fogsgaard, K. K., C. M. Røntved, P. Sørensen, and M. S. Herskin. 2012. Sickness behavior in dairy cows during Escherichia coli mastitis. J. Dairy Sci. 95:630-638.

Hart, B. L. 1987. Behavior of sick animals. Vet. Clin. North Am. Food Anim. Pract. 3:383-391.

Horvath, K. C., and E. K. Miller-Cushon. 2019. Characterizing grooming behavior patterns and the influence of brush access on the behavior of group-housed dairy calves. J. Dairy Sci. 102:3421-3430.

Hosseinkhani, A., T. J. DeVries, K. L. Proudfoot, R. Valizadeh, D. M. Veira, and M. A. G. von Keyserlingk. 2008. The effects of feed bunk competition on the feed sorting behavior of close-up dry cows. J. Dairy Sci. 91:1115-1121.

Ito, K., M. A. G. von Keyserlingk, S. J. LeBlanc, and D. M. Weary. 2010. Lying behavior as an indicator of lameness in dairy cows. J. Dairy Sci. 93:3553-3560.

Jensen, M. B., L. J. Pedersen, and L. Munksgaard. 2005. The effect of reward duration on demand functions for rest in dairy heifers and lying requirements as measured by demand functions. Appl. Anim. Behav. Sci. 90:207-217.

Krawczel, P. D., L. M. Klaiber, S. S. Thibeau, and H. M. Dann. 2012. Technical note: Data loggers are a valid method for assessing the feeding behavior of dairy cows using the Calan Broadbent Feeding System. J. Dairy Sci. 95:4452-4456.

Ledgerwood, D. N., C. Winckler, and C. B. Tucker. 2010. Evaluation of data loggers, sampling intervals, and editing techniques for measuring the lying behavior of dairy cattle. J. Dairy Sci. 93:5129-5139.

Macdonald, P., and J. Du. 2018. mixdist: Finite Mixture Distribution Models. R package version 0.5-5. Accessed Mar. 5, 2019. https:// CRAN.R-project.org/package $=$ mixdist.

Mellor, D. J., C. J. Cook, and K. J. Stafford. 2000. Quantifying some responses to pain as a stressor. Pages 171-198 in The Biology of Animal Stress-Basic Principles and Implications for Animal Welfare. G.P. Moberg and J. Mench, ed. CABI Publishing, Wallingford, UK.

Mintline, E. M., M. Stewart, A. R. Rogers, N. R. Cox, G. A. Verkerk, J. M. Stookey, J. R. Webster, and C. B. Tucker. 2013. Play behavior as an indicator of animal welfare: Disbudding in dairy calves. Appl. Anim. Behav. Sci. 144:22-30.

Mølgaard, L., B. M. Damgaard, V. Bjerre-Harpøth, and M. S. Herskin. 2012. Effects of percutaneous needle liver biopsy on dairy cow behavior. Res. Vet. Sci. 93:1248-1254.

Newby, N. C., C. B. Tucker, D. L. Pearl, S. J. LeBlanc, K. E. Leslie, M. A. G. von Keyserlingk, and T. F. Duffield. 2014. An investigation of the effects of ketoprofen following rumen fistulation surgery in lactating dairy cows. Can. Vet. J. 55:442-448.

Norring, M., J. Haggman, H. Simojoki, P. Tamminen, C. Winckler, and M. Pastell. 2014. Short communication: Lameness impairs feeding behavior of dairy cows. J. Dairy Sci. 97:4317-4321.

Siivonen, J., S. Taponen, M. Hovinen, M. Pastell, B. J. Lensink, S. Pyörälä, and L. Hänninen. 2011. Impact of acute clinical mastitis on cow behavior. Appl. Anim. Behav. Sci. 132:101-106.

Skibiel, A. L., B. Dado-Senn, T. F. Fabris, G. E. Dahl, and J. Laporta. 2018. In utero exposure to thermal stress has long-term effects on mammary gland microstructure and function in dairy cattle. PLoS One 13:e0206046.

Thüer, S., S. Mellema, M. G. Doherr, B. Wechsler, K. Nuss, and A Steiner. 2007. Effect of local anaesthesia on short- and long-term pain induced by two bloodless castration methods in calves. Vet. J. 173:333-342.

Weng, X., A. P. A. Monteiro, J. Guo, B. M. S. Ahmed, J. K. Bernard, D. J. Tomlinson, J. M. DeFrain, G. E. Dahl, and S. Tao. 2017. Short communication: Repeated mammary tissue collections during lactation do not alter subsequent milk yield or composition. J. Dairy Sci. 100:8422-8425.

West, J. W. 2003. Effects of heat-stress on production in dairy cattle. J. Dairy Sci. 86:2131-2144.

\section{ORCIDS}

E. K. Miller-Cushon ㄴ https://orcid.org/0000-0003-1876-807X

K. C. Horvath ๑ https://orcid.org/0000-0002-5345-6509

G. E. Dahl ๑ https://orcid.org/0000-0002-2182-6317

J. Laporta @ https://orcid.org/0000-0002-3186-5360 